\title{
ANALISIS KEGAGALAN SPRING WASHER MATERIAL SK-5 LAPISAN ELECTROPLATING ZINC
}

\author{
Muhammad Tegar ${ }^{1)}$, Edi Sutoyo ${ }^{2)}$ \\ ${ }^{1}$ Program StudiTeknik Mesin, Universitas Ibn Khaldun Bogor \\ e-mail: muhammadtegar@gmail.com \\ ${ }^{2}$ Program StudiTeknik Mesin, Universitas Ibn Khaldun Bogor \\ e-mail: edi.sutoyo@ft.uika-bogor.ac.id
}

\begin{abstract}
ABSTRAK
Spring washer merupakan salah satu komponen yang digunakan pada industri otomotif berfungsi sebagai sistem penggerak atau penahan pada suatu unit assembly. Spring washer juga dapat berfungsi sebagai pegas pada mekanisme beban berat. Spring washer harus memiliki spesifikasi tinggi untuk menghindari kegagalan fungsi. Dalam penelitian ini dilakukan investigasi terhadap kegagalan fungsi (patah) spring washer setelah dilakukan assembly unit. Investigasi dilakukan untuk mengetahui penyebab terjadinya dan jenis patahan pada spring washer. Analisa dilakukan terhadap aktual proses manufaktur, serta beberapa pengujian diantaranya uji komposisi kimia material SK-5, uji kekerasan, SEM serta foto mikro. Hasil pengujian dan observasi jenis patahan termasuk jenis moderate ductile-brittle, penyebabnya adalah adanya inisial crack membentuk flow mark, proses tempering rendah di temperatur $240^{\circ} \mathrm{C}$, proses acid pickling tidak sempurna, tidak dilakukan proses baking out selama 4 jam pada temperatur $200^{\circ} \mathrm{C}$, patahan terjadi setelah spring washer menerima beban sebesar $1928 \mathrm{~N}$ (192,8 kgf), patahan memiliki kekerasan 62-65 HRC serta distribusi kekerasan tidak merata 720-780 HV kedalaman 0,5 mm. Hasil SEM adanya pembentukan avoid menandakan $100 \%$ retakan intragranular dan foto mikro menunjukan adanya inisial tidak homogen yang terbentuk pada fase martensit pada perbesaran 100x. Dari hasil pengujian dan observasi dapat disimpulkan bahwa fenomena patahan pada spring washer terjadi karena hydrogen embrittlement yang terjebak di dalam lapisan electroplating zinc membentuk pitting corrosion sepanjang area flow mark sehingga terbentuk butiran retakan intragranular serta tidak tercapainya temperatur tempering di angka $550^{\circ} \mathrm{C}$ sehingga menimbulkan kerapuhan pada spring washer saat menerima beban berat.
\end{abstract}

Kata kunci : Assembly, Flow Mark, Hydrogen Embrittlement, Patahan, Spring Washer.

\section{ABSTRACT}

Spring washer is one of the components used in the automotive industry to function as a drive system in an assembly unit that is able to hold or function as a spring in a heavy load mechanism, so this component must have high specifications to avoid damage to the assembly unit. This study aims to investigate spring washers that do not function on the two-wheeled components after the assembly unit. To find out the cause of disruption to the spring washer it is necessary to investigate the type of damage, the actual manufacturing process of the spring washer, the SK-5 material spectrometer test, the hardness of the spring washer, SEM and micro photographs. Test and Observation Results: fracture including the type of moderate brittle, the presence of initial cracks that form flow marks, the process of low temper at $240^{\circ} C$, acid preservation process is not perfect, there is no manufacturing process for 4 hours at $200^{\circ} \mathrm{C}$, the fracture occurs after the spring washer receives a load of $1928 \mathrm{~N}(192.8 \mathrm{kgf})$, the fault has a hardness of 62-65 HRC and an uneven distribution of hardness from a depth of 720-780 HV 0.5 mm. SEM results from avoid formations show $100 \%$ intragranular cracks and microstructure shows that no homogeneous initials are formed in the martensite phase at 100x magnification. From the results of tests and observations it can be concluded that the phenomenon of fracture in the spring washer occurs due to hydrogen embrittlement trapped in a zinc electroplating layer forming pitting corrosion along the flow marking area so that intragranular cracks are formed and tempering temperatures are not reached. at $550^{\circ} \mathrm{C}$. spring washer when receiving heavy loads.

Keywords : Assembly, Flow Mark, Hydrogen Embrittlement, Fracture, Spring Washer. 


\section{PENDAHULUAN}

Industri Otomotif merupakan industri terbesar di Indonesia. Berbagai produk baik produk eksterior maupun interior dan produk metal baja serta produk karet sudah menjadi produk-produk unggulan di beberapa perusahan besar di Indonesia. Jaminan kualitas produk sudah menjadi persyaratan utama sehingga perlu adanya tindakan pengawasan terhadap proses manufaktur dari raw material hingga barang jadi,

Kegagalan produk seperti patahan pada produk metal baja karbon tinggi diperlukan analisa khusus dalam menanggulangi penyebab dari kegagalan atau kondisi abnormal tersebut. Menurut Knott (1973) ; Broek (1982), patahan pada metal baja karbon tinggi seperti patahan ductile, brittle, dan moderate ductile. Diawali adanya strecth mark atau initial crack pada produk, hal ini disebabkan adanya proses abnormal pada penggunaan disertai beban berat melebihi kapasitas produk ataupun pada proses pembuatan produk seperti kegagalan dalam proses heat treatment (Ashby dan Jones, 1980). Menurut Newman dan Procter (1990), penyebab lain patahan pada baja karbon yang terjadi adanya korosi membentuk pitting korosi /sumuran korosi yang menyebabkan Stress Corrosion Cracking.

Menurut Ashadi et al. (2002), terjadinya karat merupakan hasil korosi, yaitu oksidasi suatu logam. Besi yang mengalami korosi membentuk karat dengan rumus $\mathrm{Fe}_{2} \mathrm{O}_{3} \cdot \mathrm{xH}_{2} \mathrm{O}$. Korosi atau proses pengaratan merupakan proses elektro kimia. Pada proses pengaratan, besi $(\mathrm{Fe})$ bertindak sebagai pereduksi dan oksigen $(\mathrm{O} 2)$ yang terlarut dalam air bertindak sebagai pengoksidasi. Karat yang terbentuk pada logam akan mempercepat proses pengaratan berikutnya. Oleh sebab itu, karat disebut juga dengan autokatalis (Trethewey dan Chamberlain, 1991).

Mekanisme terjadinya korosi adalah logam besi yang letaknya jauh dari permukaan kontak dengan udara akan dioksidasi oleh ion $\mathrm{Fe}^{2+}$. Ion ini larut dalam tetesan air. Tempat terjadinya reaksi oksidasi di salah satu ujung tetesan air ini disebut anode. Ion $\mathrm{Fe}^{2+}$ yang terbentuk bergerak dari anode ke katode melalui logam. Elektron iniselanjutnya mereduksi oksigen dari udara dan menghasilkan air. Ujung tetesan air tempat terjadinya reaksi reduksi ini disebut katode. Sebagian oksigen dari udara larut dalam tetesan air dan mengoksidasi $\mathrm{Fe}^{2+}$ menjadiFe ${ }^{3+}$ yang membentuk karat besi $\left(\mathrm{Fe}_{2} \mathrm{O}_{3} \cdot \mathrm{H}_{2} \mathrm{O}\right)$. Sifat-sifat kimia yang mempengaruhi korosi: $\mathrm{PH}$, Alkalinitas,
Oksigen terlarut DO (dissolved oxygen), SS (suspended Solid), Kalsium, Klorida, Acid dan Sulfat, (Uhlig, 2011). Dari penjelasan korosi pitting atau sumuran bisa antipasi dengan melalui proses electroplating. Dimana potensi terjadi korosi pitting bisa ditutup oleh lapisan di atas base metal untuk meminimalisir terjadinya oksidasi.

Pelapisan electroplating pada baja bisa menimbulkan hydrogen embrittlement ketika ditemukan proses abnormal pada proses acid pickling. Menurut (Bernstein dan Thompson, 1981), akibat proses tidak sempurna saat acid picking menghasilkan endapan atau void hidrogen pada lapisan electroplating yang mempunyai sifat merusak dan rapuh atau getas (Barsom dan Rolfe, 1987). Menurut Herring (2006), secara penampakan adanya faktor hydrogen embrittlement pada produk adanya blister atau calon karat seperti titik putih menandakan pitting korosi hal ini terjadi adanya proses tempering yang tidak sempurna dan faktor impuritas saat proses electroplating.Tujuan penelitian ini adalah mengungkap studi kasus fenomena patahan pada komponen spring washer dan mengalami beban.

\section{METODE PENELITIAN}

Penelitian ini dilakukan di Laboratorium Manufaktur, Program Studi Teknik Mesin, Fakultas Teknik dan Sains, Universitas Ibnu Khaldun Bogor. Dengan mengikuti diagram alir seperti gambar 1.

Spesifikasi material dan alat pengujian dalam penelitian ini diantaranya:

- Material SK-5

- Scanning Electron Metalograph (SEM)

- Hardness Rockwell testing

- Hardness Vickers

- Foto mikro

- Spectrometer

Spesifikasi proses pada penelitian ini sebagai berikut:

- Lapisan Electroplating Zinc

- Proses Baking

- Heat treatment media oil temper 


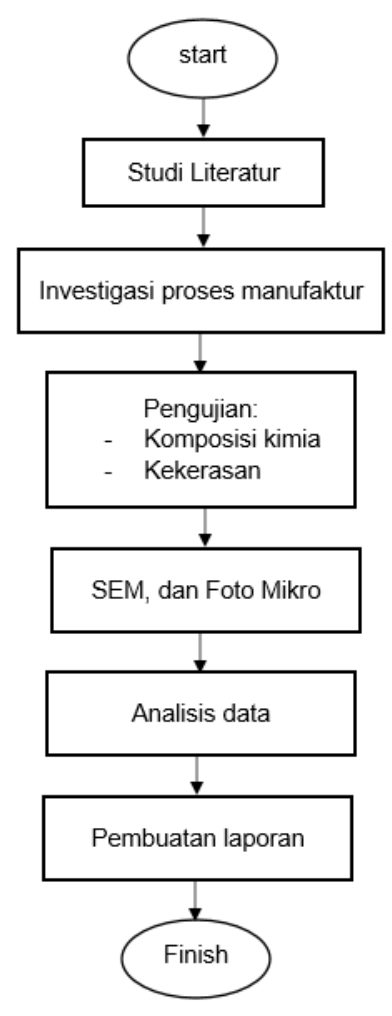

Gambar 1. Diagram Alir penelitian

\section{HASIL DAN PEMBAHASAN}

Bentuk visual patahan spring washer terlihat seperti pada gambar2. Spring washer terbagi menjadi beberapa bagian akibat pembebanan saat proses assembly. Pengujian material SK-5 menggunakan spectrometer dengan dilakukan pengujian 3 titik yang berbeda (Gambar 4). Nilai komposisi kimia masih dalam batas standard JIS G 4401. Hal ini menunjukkan bahwa produk spring washer pada dasarnya masih masuk kedalam kategori material standard.

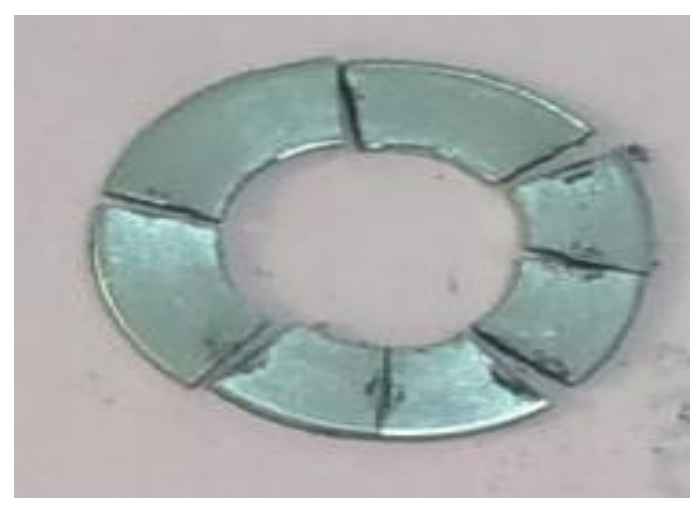

Gambar 2. Visualisasi patahan spring washer

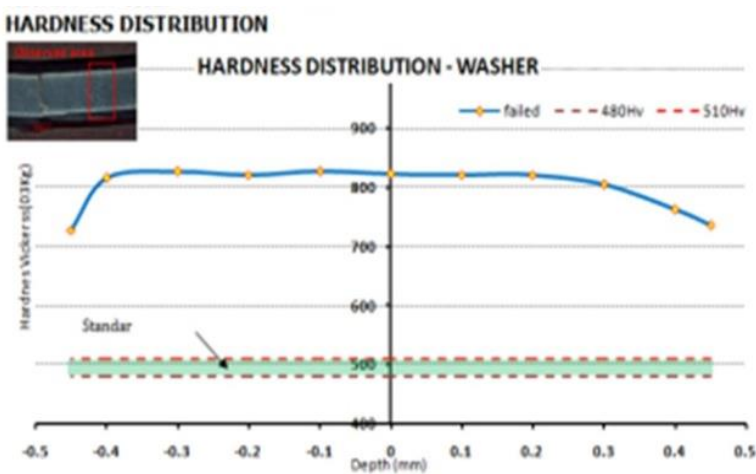

Gambar 3. Uji komposisi kimia SK-5 dilakukan 3 titik inspeksi

Hasil observasi patahan spring washer memiliki nilai kekerasan $62 \mathrm{HRC}$ hingga $63 \mathrm{HRC}$ ditunjukkan pada Gambar 4. Hal ini menunjukkan bahwa nilai kekerasan yang terjadi pada spring washer masih ke dalam batas level atas fasa martensite. dimana level nilai kekerasan fasa martensite berada pada titik kekerasan 20-65 HRC dengan baja carbon $>0.8 \%$ pada proses oil tempering. Namun dari hasil nilai produk spring washer menunjukkan adanya penyebaran kekerasan dengan nilai fluktuatif yang tinggi diantara 720$820 \mathrm{HV}$ nilai prediksi standar hal ini menunjukkan adanya ketidakseimbangan waktu tempering pada proses oil tempering.

\section{Hardness Value}

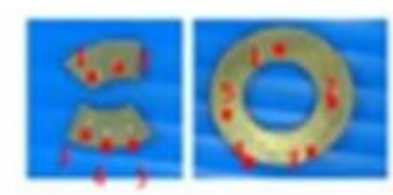

\begin{tabular}{lcccccc}
\hline \multicolumn{1}{c}{ Washer Spring } & \multicolumn{7}{c}{ Result } \\
\hline & AVE & 1 & 2 & 3 & 4 & 5 \\
\hline Fracture & 62 & 62 & 63 & 63 & 62 & 63 \\
\hline Other (lot fracture) & 64 & 64 & 64 & 64 & 64 & 64 \\
\hline
\end{tabular}

Gambar 4. Hasil uji HRC

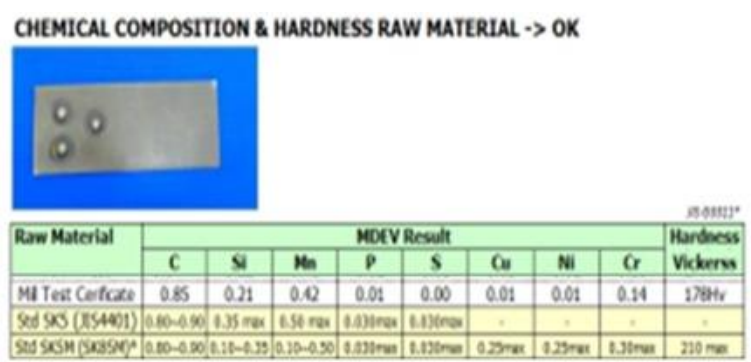

Gambar 5. Distribusi kekerasan hardness (HV) 
Ketika terjadi perubahan waktu tempering maka akan menghasilkan nilai kekerasan yang rendah. Hal ini disebabkan adanya partikel yang menyatu dengan tumbuhnya ukuran grain dan meningkatnya jarak interpartikel dari ferrit yang lebih lunak sehingga membuat getas pada produk spring washer karena efek kondisi abnormal proses oil tempering. Hasil pengamatan uji Scanning Electron Magnifaction (SEM) dengan 3 titik inspeksi berbeda pada Gambar 6 menunjukkan adanya retakan intragranular dengan membentuk area void seperti Gambar 6. menandakan adanya hidrogen yang terjebak di dalam base material menimbulkan Hydrogen Stress Cracking (HSC) yang menyebabkan kerusakan pada produk spring washer patah.

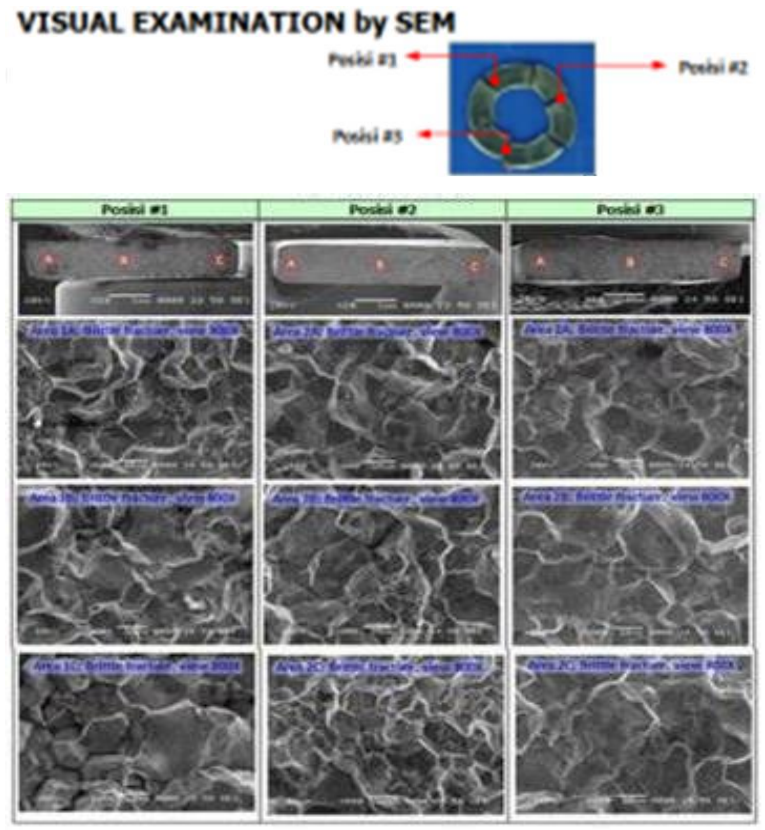

Gambar 6. Hasil uji SEM

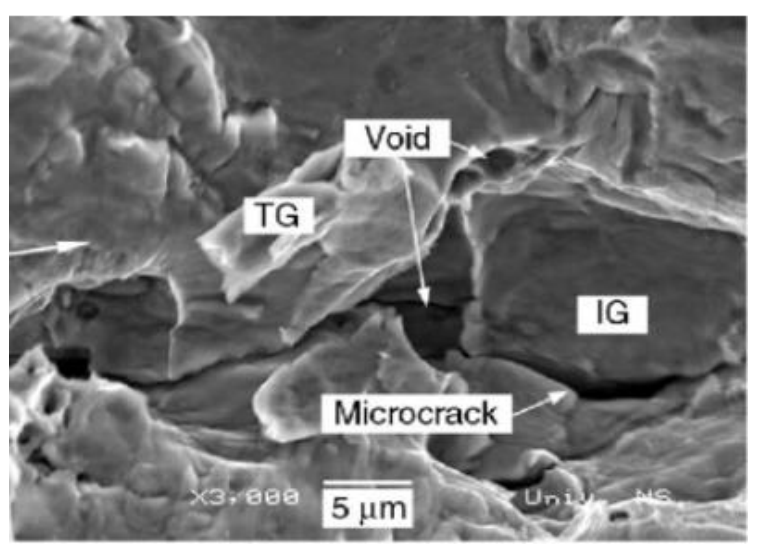

Gambar 7. Pembentukan hydrogen embrittlement
Hasil pengamatan visual pelapisan electroplating (Gambar 8) adanya korosi merah yang membentuk sumuran korosi menandakan bahwa tingkat asam yang tinggi melalui proses acid pickling tidak sempurna menghasilkan fasa hidrogen menjadi kumpulan gas yang teroksidasi menjadi karat.

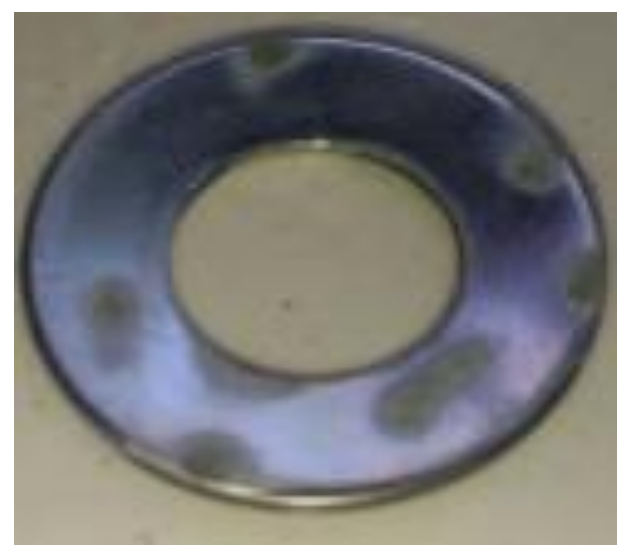

Gambar 8. Visualisasi kegagalan proses electroplating

dari Gambar 7 dan Gambar 8 pembentukan crack serta void intragranular yang terlihat dari foto mikro menunjukan bahwa adanya hidrogen di dalam base metal pelapisan zinc merupakan indikasi adanya waktu proses baking yang tidak sempurna. Hasil pengamatan fotomikro yang ditunjukkan pada Gambar 10 adanya pitting corrosion dan beach mark karena bentukan intragranular yang menjalar ke beberapa partikel atau grain material yang dilapisi zinc electroplating.

Hasil pengamatan terhadap proses hardening (gambar 9) menunjukan adanya waktu tempering pada $230^{\circ} \mathrm{C}$ yang merupakan indikasi atau potensi kerapuhan pada baja sehingga baja tidak mampu menahan beban berat. Hal ini sebabkan adanya sisa tegangan yang tidak sempurna (Gambar 12) karena dipengaruhi tidak tercapainya temperatur tempering di temperatur $550^{\circ} \mathrm{C}$ sehingga titik kerapuhan akan merambat membentuk patahan moderat ductile-brittle seperti yang ditunjukkan pada Gambar 13.

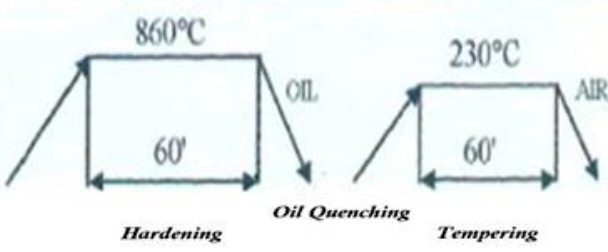

Gambar 9. Grafik proses hardening 


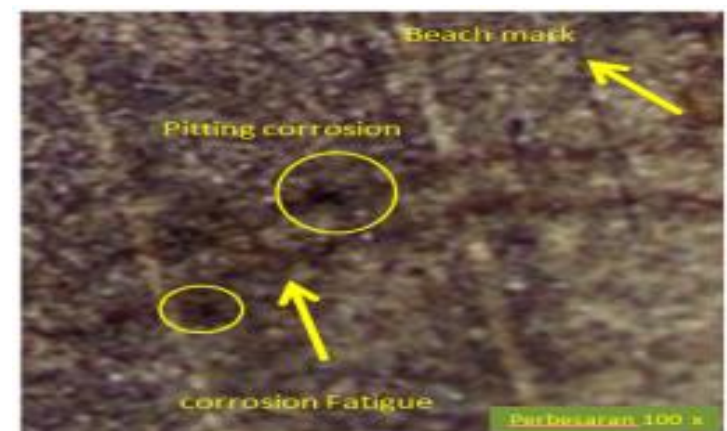

Gambar 10. Fotomikro

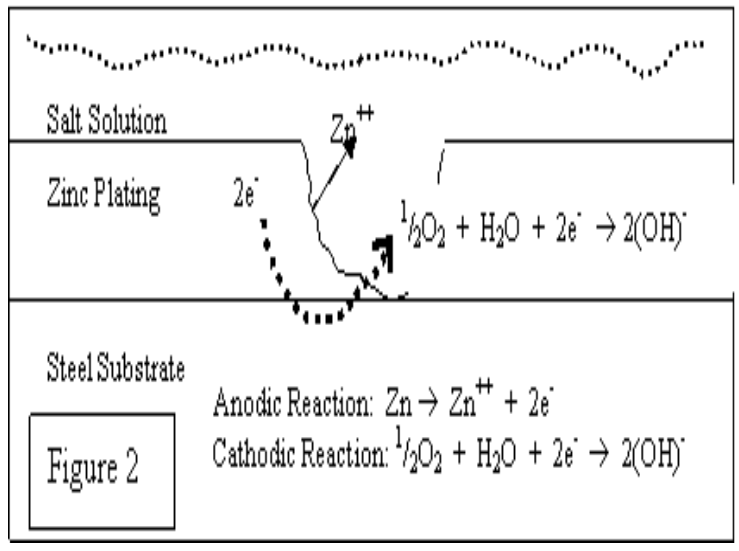

Gambar 11. Fasa reaksi korosi pada pelapisan zinc terhadap metal

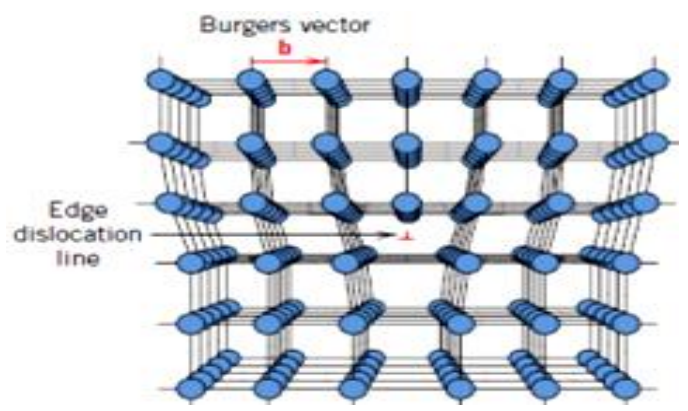

Gambar 12. Ilustrasi sisa tegangan tidak sempurna dipengaruhi oleh adanya area dislokasi partikel

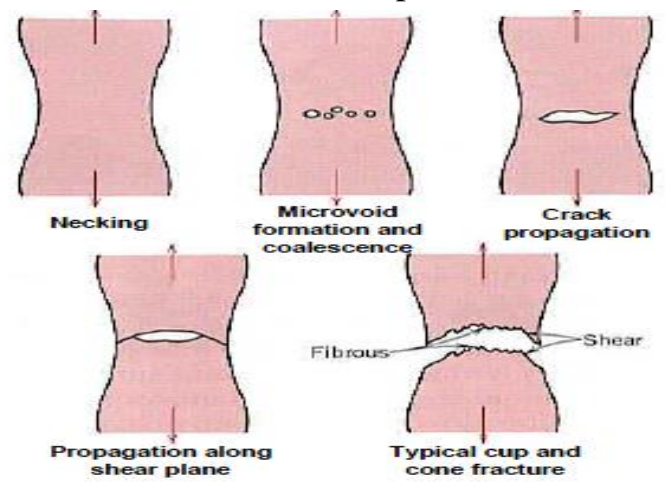

Gambar 13. Patahan jenis moderate ductile-brittle

\section{KESIMPULAN DAN SARAN}

Hasil investigasi proses produksi, rangkaian pengujian dan analisis patahan pada spring washer dapat dapat disimpulkan, spring washer Hardness 62-64 HRC masih kedalam fasa martensite dan batas kekerasan HRC, C $=0,80-0,90 \%$. Spring washer patah adanya penyebaran kekerasan $\mathrm{HV}$ yang tidak merata yang di sebabkan karena proses tempering di bawah $350^{\circ} \mathrm{C}$ (Rapuh ke brittle). Spring washer patah part tidak $100 \%$ Intergranular. Spring washer patah adanya pembentukan pitting korosi dari reaksi kimia selama pembentukan asam menjadi pengoksidasi dalam base metal. Spring washer patah mengalami waktu baking yang tidak sempurna sehingga hidrogen yang terjebak didalam base material menimbulkan Hydrogen Stress Cracking (HSC). Jenis Patahan termasuk Moderate ductile -brittle

Hasil dari rangkaian pengujian dan analisa patahan pada spring washer maka disarankan adanya penambahan waktu proses baking. hindari bahaya hydrogen embrittlement pada base metal karbon tinggi $>0,60 \%$. Hindari bahaya asam acid pada base metal pada proses surface treatment. Proses hardening menggunakan media salt Austampering (fasa bainid)

\section{REFERENSI}

Ashadi, H. W., Sulistyoweni, W., Gusniani, I. (2002). Pengaruh unsur-unsur kimia korosif terhadap laju korosi tulangan beton: II. Di dalam lumpur rawa. Makara Journal of Technology, 6(2).

Ashby, M. F., Jones, D. R. H. (1980). Engineering Materials: An Introduction to Their Properties and Applications. New York: Pergamon Press

Barsom, J. M., Rolfe, S. T. (1987). Fracture and fatigue control in structures: applications of fracture mechanics.

Bernstein, I. M., Thompson, A. W. (1981). Hydrogen effects in metals. Warrendale, PA, Metallurgical Society of AIME, 1981, $1071 \mathrm{p}$.

Broek, D. (1982). Elementary engineering fracture mechanics: Springer Science \& Business Media.

Herring, D. H. (2006). The Heat Treat DoctorTMThe Embrittlement Phenomena in Hardened \& Tempered Steels. Industrial Heating, 73(10), 16-19. 
Knott, J. F. (1973). Fundamentals of fracture mechanics: Gruppo Italiano Frattura.

Newman, R. C., Procter, R. P. M. (1990). Stress corrosion cracking: 1965-1990. British Corrosion Journal, 25(4), 259-270. doi: $10.1179 / 000705990799156373$

Trethewey, K. R., Chamberlain, J. (1991). Korosi untuk mahasiswa dan Rekayasawan. Jakarta: Gramedia.

Uhlig, H. H. (2011). Uhlig's corrosion handbook (Vol. 51): John Wiley \& Sons. 